María Medina*, Silvia Santiá**, Silvia Costanzo***,

Mara Carmignani****, Claudia Rosa ${ }^{* * * * *}$

\title{
La vivienda moderna Argentina, miradas desde la periferia: Córdoba, Tucumán y Rosario'.
}

The modern Argentine housing, views from the periphery: Cordoba, Tucuman and Rosario.

Cómo citar:

Medina, M., Santiá, S., Costanzo, S., \& Rosa, C. (2018). La vivienda moderna argentina, miradas desde la periferia: Córdoba, Tucumán y Rosario. Designia, 6(1), 29-51

${ }^{1}$ Artículo de reflexión derivado de las investigaciones realizadas por la Cátedra de Historia de la Arquitectura Latinoamericana de la Facultad de Arquitectura, Urbanismo y Diseño de la Universidad de Córdoba (Argentina).

*Medina, María Rebeca. Arquitecta FAUDI, UNC. Master Internacional Rehabilitación del Patrimonio Edificado. CICOP, España. Master Gestión del Patrimonio y Desarrollo Territorial, Universidad Mayor de San Simón, Bolivia. Docente Investigador Prof. Adjunto, Cátedra de Historia de la Arquitectura IA y IIIA, FAUD-UNC. Directora del Museo Virtual de Arquitectura, UNC. Miembro CICOP España y Argentina; ICOMOS Argentina, Consultora UNESCOICOMOS Asesora Honoraria Comisión Nacional de Museos, Monumentos y Lugares Históricos. E-mail: omrebecamedina@gmail.com ORCID: 0000-0003-2094-5143

**Santiá, Silvia. Universidad Nacional de Córdoba, Argentina Arquitecta. Profesora e Investigadora en la mencionada universidad. Miembro del Equipo Profesional que realizó la Restauración y Puesta en Valor del CABILDO HISTÓRICO de la Ciudad de Córdoba , Argentina (1988- 1991). Ha participado en numerosas publicaciones entre las que se destacan : "Alta Gracia: evolución histórica y desarrollo

urbano-arquitectónico", "Lo inmaterial en el patrimonio material de la construcción en Argentina" , "la Historia de la Arquitectura de Córdoba. Construcción de una Teoría para su interpretación .Siglo XX 1955-2010". E-mail: silviamsantia@yahoo.com, ORCID: 0000-0002-6562-3124
Palabras clave:

Transculturación, modelo, identidad, región, centro, periferia

Key words:

Transculturation, model, identity, region, center, periphery.

Recibido: 19/10/2017

Aceptado: 19/09/2018 
${ }^{* * *}$ Costanzo, Silvia Beatriz. Arquitecta, FAUDI, UNC. 'Specialista in Restauro dei Monumenti’ Universitá La Sapienza, Roma Italia. Prof. Asistente Cátedras Introducción a la Historia de la Arquitectura y el Urbanismo B, Historia de la Arquitectura I B, Historia de la Arquitectura III A (Latinoamericana y Argentina) FAUDI, UNC. Docente Investigadora SECYT UNC. Miembro ICOMOS Argentina. E-mail: arq.silviacostanzo@gmail.com ORCID: 0000-0002-2252-1224

****Carmignani, Mara Gabriela .Arquitecta FAUDI, UNC, 2007.Magister "Conservación y Rehabilitación del Patrimonio Arquitectónico", FAUDI, UNC 2016. Docente Investigador Categoría 5, FAUDI y Profesor asistente Cátedra de "Historia de la Arquitectura y el Urbanismo Latinoamericanos III A, UNC. Prof. Asistente, Cátedras de "Historia del Arte B" y "Arquitectura y Urbanismo", Facultad de Derecho. UNLZ. E-mail: maritacarmignani@gmail.com ORCID: 0000-0002-9658-9926

******Rosa, Claudia Beatriz. Arquitecta FAUDI, Universidad Nacional de Córdoba, 1990. Postgrado en Desarrollo de Emprendimientos Inmobiliarios,

Escuela de Economía y Negocios Universidad de Belgrano, Buenos Aires. Primer Módulo de la Maestría en Desarrollo Urbano y Regional, Secretaria de Investigación y Postgrado FAUDI, UNC. Doctorando en Doctorado de Arquitectura, DOCTA, FAUDI, UNC. Docente investigador FAUDI, Catedra de Historia de la Arquitectura y el Urbanismo Latinoamericanos III A, FAUDI, UNC. E-mail: claurosa1111@gmail.com

Las autoras agradecen la colaboración de Carolina Rasino y Paola Molero.

Resumen:

Entre las diferentes tipologías, la vivienda constituye el tipo constante a lo largo de la historia. En tal condición, es el más acertado para abordar el análisis de cómo llegan los modelos centrales a la realidad argentina en un incipiente movimiento moderno durante la primera parte del siglo XX. El epicentro receptor de esas nuevas ideas es Buenos Aires y como adherente principal a las respuestas universales, es a la vez el emisor de tales respuestas a provincias como Córdoba, Tucumán y Rosario, las cuales buscan desde el 
interior de las regiones la propia arquitectura entre posturas particulares y exógenas. Con el propósito de reflexionar acerca de las distintas miradas a ese movimiento moderno transculturado, en el presente artículo se recurre a casos de estudios concretos en los que cada exponente busca dotar de identidad a las propuestas formales mediante la comprensión del espíritu del lugar y del tiempo, para generar así soluciones singulares en el territorio argentino.

\section{Abstract:}

Housing is the constant type amongst different ones throughout history. It is therefore the most appropriate to address the analysis on how central models reach the Argentinian reality in an incipient modern movement during the twentieth century's first part. Buenos Aires is the epicenter for the new ideas and as the main adherent to the universal responses, it issues at the same time those responses to provinces such as Córdoba, Tucumán and Rosario, which from their inner regions look for their own architecture by developing particular and exogenous positions. Aiming to reflect on the distinct views associated to this modern transcultural movement, this paper goes through case studies where the formal proposals are intended to be provided with identity by understanding the spirit of both the place and the time, thus generating unique projects in Argentina.

\section{INTRODUCCIÓN}

Desde la cátedra Historia de la Arquitectura Latinoamericana III-A se intenta generar una actitud reflexiva y crítica frente a la producción arquitectónico-urbanística de Latinoamérica en distintos momentos y diversos contextos geográficos y culturales. Dicha producción y sus procesos de diseño son abordados desde un análisis gráfico-conceptual, integral y crítico de varias tipologías a través de diferentes períodos históricos (desde el prehispánico hasta la actualidad). El enfoque teórico de la cátedra debe permitir arribar a una conclusión crítica para verificar la aplicación de conceptos instrumentales y pares dialécticos: los procesos de transculturación, la relación centro-periferia, tradición y vanguardia, entre otros. Las conclusiones y comparaciones a las que se llega favorecen la identificación de disímiles actitudes de diseño, según el "espíritu de la época" y el "espíritu del lugar", al decir de Enrique Browne (1988), las cuales introducen innovaciones en el "tipo" arquitectónico. 
Interesa, por lo tanto, indagar en los resultados del proceso de diseño centrados en la transculturación del movimiento moderno (MoMo), su anclaje e influencia en el desarrollo de la vivienda -uno de los tipos constantes a lo largo de la historia- por parte de arquitectos que desempeñaron su actividad profesional en diferentes zonas geográficas y contextos sociales del país, como son Córdoba y Rosario de la región centro y Tucumán del noroeste argentino, realidades disímiles entre sí y a su vez en su relación con Buenos Aires, epicentro del quehacer arquitectónico.

Ese centro y esas periferias implican miradas distintas al transculturado modelo moderno. Desde las ciudades donde la producción arquitectónica provincial es centralizada, hay "otra" mirada que muchas veces tiene en cuenta -a pesar de lo internacional de las propuestas- condiciones regionales por las cuales se anticipa el concepto de "otra arquitectura" de Browne: usar otros materiales, reelaborar el modelo, construir lugares, buscar innovaciones formales que identifiquen al autor.

Desde el enfoque pedagógico de la cátedra, el estudio del tipo funcional de la vivienda implica reflexionar sobre los procesos de diseño de cada autor y sus "otras" circunstancias en la diversidad del territorio argentino, con el fin de vincularlos con la experiencia proyectual de un alumno de cuarto nivel de la carrera de Arquitectura.

Como objetivos particulares del presente artículo, se pretende generar una mirada crítica hacia las propuestas de los autores de la otra argentina; visualizar cómo cada caso interpreta los modelos MoMo desde el centro a las periferias; e identificar en cuáles se verifican influencias regionales o adherencias al modelo universal. 


\section{LA VIVIENDA COMO TIPO FUNCIONAL DE ANÁLISIS}

Waisman (1995) define el tipo arquitectónico como el sistema de relaciones tipológicas entre elementos espaciales y formales que se corresponden con un sistema de coordinación de funciones y otro estructural que no implica definiciones formales. Ha sido formado, ya sea por generalización de una creación individual o por abstracción de diversos edificios; está ligado en su origen a condiciones históricas y en ocasiones a propuestas generales a partir de las cuales se constituye una carga significativa.

En lo referente a la identidad cultural latinoamericana, puede decirse que es dinámica y cambiante, permeable a circunstancias propias y exógenas, un proceso continuo y multifacético construido día a día. La vivienda en Latinoamérica evidencia claramente estas características a inicios del siglo XX al adherir a la vanguardia planteada por el MoMo europeo, si bien incorpora la impronta de culturas particulares en ejemplos paradigmáticos de reelaboración y apropiación. Coexisten con estas otras miradas ancladas en un pasado referente de "lo propio" americano, no exento de los aportes generados en el mestizaje de lo indígena y los modelos coloniales transculturados.

En esta búsqueda de identidad, factible de encontrarse materializada en la vivienda, se abre otra opción de diseño: una síntesis que podía resultar en arquitectura moderna pero verdaderamente nuestra, aunque no siempre se consideraba necesario incluir el factor local. Los argentinos Vautier y Prebisch (1924) entendían que al despojarse del pasado y las tradiciones podían considerar, con mayor objetividad, las condiciones de vida moderna en correspondencia con la idea de espíritu de la época. No hablaban del espíritu del lugar ni de la herencia urbano-arquitectónica de más de cuatro siglos. Posiblemente coincidían con Warchavchik (1928) cuando afirmaba: "los pueblos de reciente formación como los americanos, no tienen tradición que contemplar... sino conquistas a efectuar" (citado por Gutiérrez, 2002, p. 581-582). Ahora bien, cabe preguntar si las viviendas diseñadas en el territorio argentino a partir de las pautas del MoMo fueron símbolos de esa nueva y "otra" conquista.

\section{LA VIVIENDA EN EL SIGLO XX}

Doberti (2008), sostiene que lo propio de la arquitectura es ser habitada y lo específico de la acción humana de habitar es su carácter histórico, mutable y múltiple. En los modos de ocupar el espacio para habitarlo se ponen en juego cuestiones políticas y sociales, biológicas y simbólicas, organizativas y rituales, y son estos modos los que definen los rasgos esenciales de nuestra identidad personal, grupal y cultural. 
Romero (1997) señala que la aproximación al conocimiento de los cambios de la vivienda y sus expresiones territoriales puede aportar claves para ulteriores análisis en las dimensiones sociales y culturales, ya que el espacio doméstico provee un registro privilegiado de huellas de las acciones y los comportamientos de los individuos.

La casa, según Josep Montaner (2011), es como un microcosmo en el universo. Crea un mundo que a veces se abre hacia el paisaje, donde el hombre latinoamericano acumula objetos, tales como obras de arte, artesanías, plantas, árboles y libros, entre muchos otros. Quizá sea un resabio de las prácticas del antiguo colonizador y del viajero descubridor. En cuanto a la expresión arquitectónica, Montaner reconoce las viviendas unifamiliares singulares, con "autores" destacados, pertenecientes a un mundo de arquitectura culta. Por otro lado, identifica ejemplos de vivienda social unifamiliar agrupada, respuesta masiva, popular y que busca ser digna a la necesidad de habitar. Cabe además indagar acerca de cómo los autores destacados procesan los modelos del MoMo para resolver estos tipos de viviendas en regiones no centrales.

La vivienda es uno de los tipos constantes a lo largo de la historia. Como concepto instrumental de análisis, el tipo es lo representativo de lo esencial de una institución. No es un modelo ni una forma y pueden existir varios según el elemento componente de la arquitectura que se seleccione para los fines del análisis (Trecco, 1979).

Al mantenerse casi constante lo esencial del tipo vivienda, es decir, espacios para reunir a la familia, otros para descansar y servicios a distintas escalas, lo variable se enfoca en el lenguaje y su significado, que incluyen la tecnología como expresión y evidencia la participación de su propietario en el juego de poder de cada época.

Según la definición de Le Corbusier, la vivienda "es una máquina para ser habitada", una forma que responde a la función y a los cincos puntos formulados por el maestro en la búsqueda de asegurar la fluidez del espacio. Al ser transculturados en Argentina, el proceso de diseño tuvo respuestas que abarcan desde materializaciones textuales de la teoría hasta modificaciones de esos cinco puntos con realidades materiales y sociales de las regiones, donde prevalece más el significado del objeto. 
El año 1924 marca un hito importante en la producción intelectual argentina. En el arte, regresa al país Emilio Petorutti y realiza una exposición de sus trabajos. Su cubismo sintético, relacionado con el purismo de Juan Gris, recibe el reconocimiento de los fundadores de la revista Martin Fierro, quienes quebraron la unidad intelectual porteña. Asimismo, en 1929 llega al país Le Corbusier, invitado por la Asociación Amigos del Arte. La arquitectura moderna servía de portavoz único de las ideas renovadoras y se expresaba, tanto en Europa como en América, en múltiples declaraciones o manifiestos. En estos últimos, las vanguardias encontraron un medio narrativo para comunicar sus principios, procedimientos y objetivos, en tanto las obras realizadas fueron la ejemplificación concreta de su proyección en la realidad (Melé, 2005). Buenos Aires, como urbe cosmopolita, no era ajeno a todo ello, pero al igual que en Europa, solo la elite intelectual de clase alta y media abrazó las ideas progresistas, la pureza y sencillez volumétrica, la simplicidad y el escepticismo en la ornamentación.

Para Liernur (2008), la modernidad argentina es un proceso plural y conflictivo en que la conformación de la arquitectura moderna se entrecruza con las historias intelectuales de las ideas estéticas, de las instituciones, del campo profesional y de la técnica. Victoria Ocampo, con su conocido carácter revolucionario, fue la primera en someterse a los dictados del nuevo movimiento en la capital del país, para lo cual persuadió al arquitecto Alejandro Bustillo a diseñarle una casa moderna. Esa arquitectura significaba liberarse de tipologías anacrónicas que satisfacían las ansias de mostrarse socialmente e incorporaba una escala humana. Así, dejaba de lado la retórica monumentalista del neoclasicismo y del academicismo para adquirir un carácter social y económico.

La arquitectura de volúmenes blancos y puros, despojada de ornamentación, utiliza sistemas constructivos modernos, distingue la estructura de la envolvente, reemplaza las estrechas ventanas decimonónicas con fajas horizontales de vidrio para dar paso a la luz solar y dejar atrás la sombría iluminación de los ambientes. Estos reducen su tamaño con el fin de lograr más intimidad, disminuyen las áreas de servicio y adoptan techos más bajos, los cuales se convierten en jardines. Adquiere categoría espacial el dúplex, derivado del atelier del pintor, con su informal relación entre zona diurna y nocturna. Esta arquitectura en que la forma sigue a la función tuvo sus pioneros en Antonio Vilar, Amancio Williams, Alberto Prebisch, Wladimiro Acosta y Alejandro Virasoro, quienes desarrollaron su actividad en Buenos Aires en la década del treinta. 
La relación centro-periferia en esta etapa de transculturación toma varias modalidades: directa, por adopción y por apropiación de la cultura moderna. Cabe preguntar cuál es el centro. ¿Hay un emisor único, como lo fue Europa, generador de la idea de base, o bien uno como Buenos Aires? Esta era una ciudad cosmopolita, portuaria, con una visión puesta en Europa desde la conquista, abierta y permeable a los cambios, a las modas, a lo nuevo, que adscribió a los postulados del MoMo a partir de una elite culta y de clase alta. Puede decirse que su cultura "estaba tensionada por 'lo nuevo', aunque también lamentara el curso irreparable de los cambios" (Sarlo, 1988, p.29).

Con causas y consecuencias diversas, con fuerzas socioculturales actuantes capaces de transformar la hegemonía metropolitana, con cierta resistencia por parte de algunos sectores, en especial estatales, el MoMo se dio con idéntica intensidad en Buenos Aires, centro receptor emisor, y en esa "otra" periferia subyacente. En ambos casos, la arquitectura moderna, generadora de un momento histórico ajeno, se estableció en Argentina y ofreció respuestas que fueron en múltiples direcciones, desde la reproducción de las construcciones lingüísticas de vanguardia de quienes no lograban entender en profundidad la verdadera esencia del "modelo", hasta respuestas arquitectónicas únicas que comprendían el espíritu del tiempo del lugar como una unidad simbiótica. Se analizan a continuación obras residenciales de figuras cuya actividad profesional se desarrolló en el interior-periferia de esa "otra Argentina".

\section{CÓRDOBA}

A principios del siglo XX la sociedad cordobesa sufrió notables transformaciones.

Las primeras décadas definieron un modelo de ciudad centrípeta, desde el centro hacia las barrancas y en torno de la red de ferrocarril. Se conformó un trazado radial que aprovechó la topografía existente con relación a los transportes de producción y las comunicaciones. Su ubicación en el centro del país potenció su rol de articulación territorial como necesario intercambiador comercial del interior (Colautti, 2002).

La ciudad evolucionó vertiginosamente al ritmo del crecimiento demográfico producido por la llegada de una considerable ola inmigratoria que al asentarse generaba nuevos barrios, mientras que una clase media en ascenso tenía la necesidad de adquirir prestigio socioeconómico. La sociedad tradicional, por su parte, fue permeable a los aires de renovación y vanguardia propuestos por la nueva era. Hacer ciudad y arquitectura durante aquellas décadas iniciales del siglo fue una labor caracterizada por una variada producción que abarcó distintas corrientes y 
lenguajes arquitectónicos, además de la introducción de tipologías emergentes y trascendentes intervenciones urbanísticas. La influencia de las primeras manifestaciones del MoMo significó una paulatina liberación de los cánones académicos, aunque la pervivencia de la idea del orden compositivo continuó por su arraigo en la esfera oficial.

\section{Un autor de la periferia en Córdoba: Ángel T. Lo Celso}

La labor de Ángel T. Lo Celso se desarrolló en décadas de continuos cambios. Inició con obras académicas y en la década del treinta se adscribió al Art Decó hasta alcanzar los ideales del MoMo en sus últimos trabajos. Hoy es más identificado con las imágenes urbanas gracias a sus edificios Art Decó. Sus fachadas escalonadas se distinguen por el uso de la línea recta y quebrada, las pilastras escalonadas que ascienden rompiendo cornisas de coronamiento, las ventanas abocinadas en ángulos rectos, las rejas con motivos geométricos estilizados, la superposición de líneas, los planos yuxtapuestos. Son características de su interpretación de un "estilo" internacional al cual otorgó un sello propio. En los interiores también surgieron tratamientos espaciales y ricos detalles en las escaleras. Los vanos se escalonaban, los hogares se trazaban con líneas quebradas y los pisos con guardas y dibujos, en tanto el damero se imponía con contraste de blanco y negro.

Casa Schunk de Kutter. Esta vivienda unifamiliar, realizada en 1932, se ubica en José María Bedoya 865, Alta Córdoba. Localizada entre medianeras, se desarrolla en dos parcelas y dos niveles. Criterios de higiene, ventilación e iluminación de todos los espacios rigen el diseño. Con ingresos peatonales y vehiculares diferenciados, en la planta baja aparecen las áreas públicas: vestíbulo, escritorio living, comedor principal, galería y hall central con escalera protagónica. El ala este alberga el sector de servicios y posee una escalera propia. En la planta alta se encuentran las zonas privadas: tres dormitorios, hall, baño, baulero y terraza. La planta manifiesta cambios tipológicos y funcionales relevantes: compactación del espacio, conexión más clara entre ambientes públicos principales, escalera protagonista del hall (como en la tipología de petit hotel) y estratificación espacial. Quedan entonces diferenciadas las áreas públicas, las privadas y de servicio. 
Las habitaciones más jerarquizadas poseen grandes aberturas y se disponen sobre la fachada. Esta, de influencia Art Decó, recurre a la división en tres paños diferenciados y unificados por la composición general, en tanto el cuerpo central contiene los aventanamientos de ambos pisos en un encuadre vertical. El zócalo que sirve de base se presenta fuerte, oscuro y escalonado. Paños cuadrados (con octógonos circunscriptos y rayos desde el centro a los vértices) separan las ventanas de ambos pisos, mientras que el remate superior se da mediante una nítida y ornamentada línea recta. El ingreso destaca por su altura y acentuada ornamentación y compensa visualmente la amplia superficie del plano central con rejas de motivos geométricos y líneas verticales de ladrillos, las cuales enmarcan los conjuntos de aberturas. Se logra así un equilibrio visual a pesar de la asimetría.

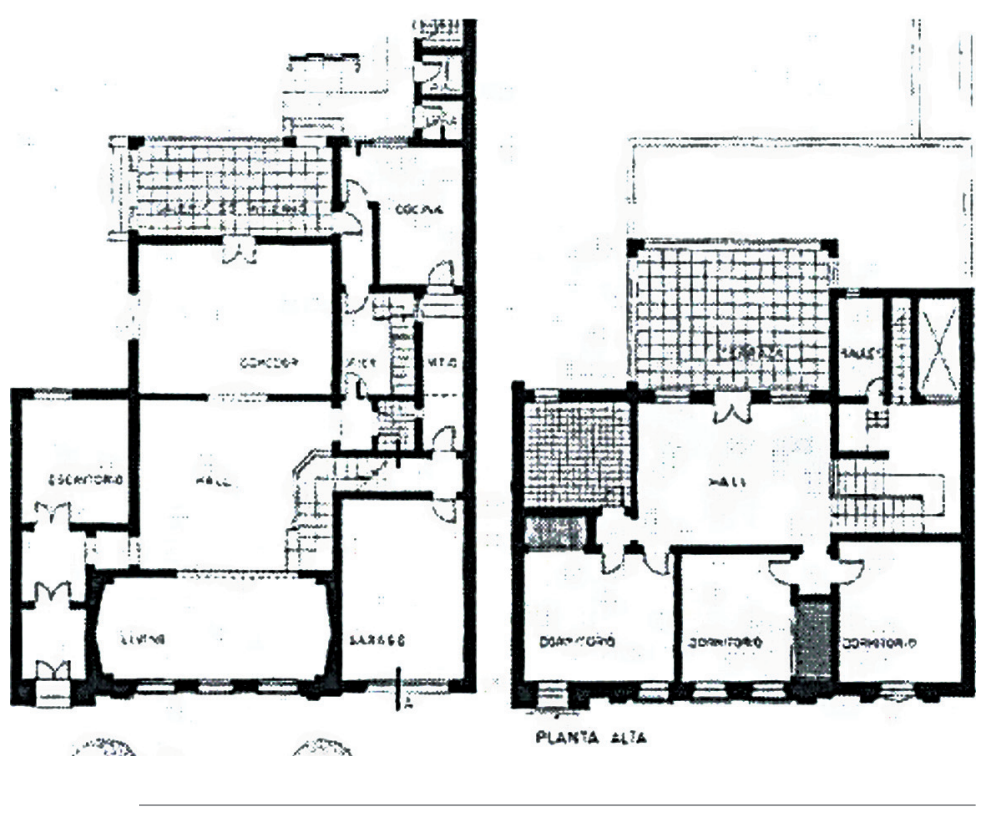

Figura 1. Plantas de la Casa Schunk de Kutter (1932), Alta Córdoba, Córdoba, Argentina. 


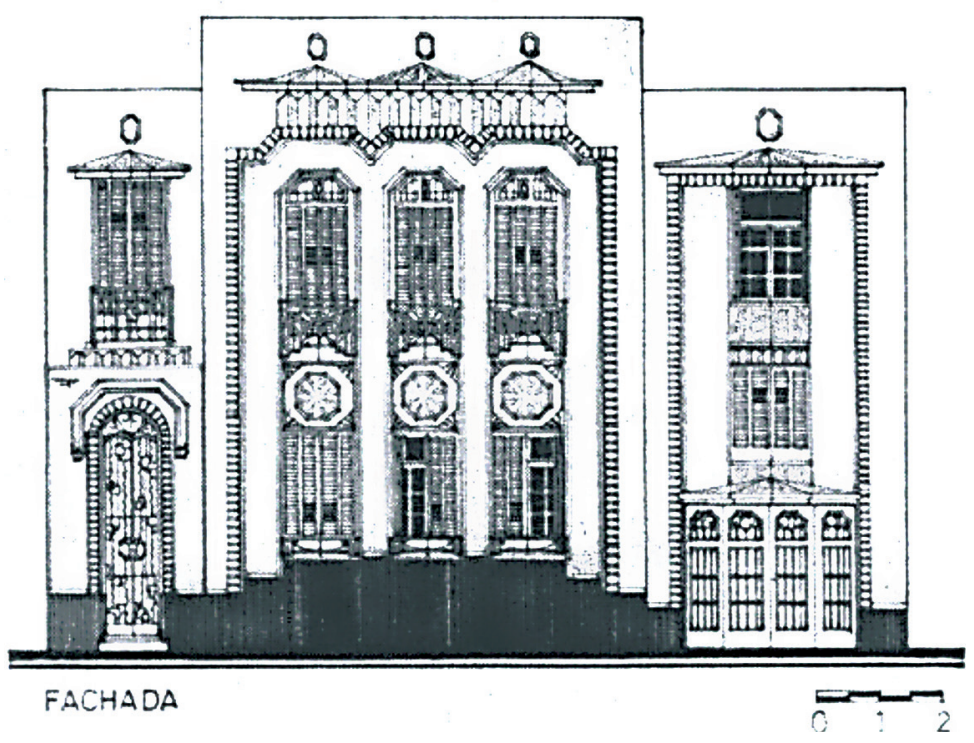

Figura 2. Elevación de la Casa Schunk de Kutter.

Fuente: autores.

Casa Sayago. Situada en 9 de julio y Mariano Fragueiro, en el centro de Córdoba, es una obra de tipología mixta construida en 1938 en la esquina de un lote de generosas dimensiones y desarrollada sobre la línea municipal. El programa se concreta en tres plantas: la baja presenta dos ingresos, uno principal al consultorio médico y sus dependencias en la esquina, en tanto el lateral conduce a la vivienda familiar. En esta planta baja se encuentran el consultorio, la espera de pacientes, el escritorio, las dependencias de servicios, un hall y la circulación vertical que conecta con la vivienda en los pisos superiores. En el primer piso, la zona diurna pública cuenta con living, escritorio, biblioteca, cocina y servicios; y en el segundo nivel aparece la zona nocturna privada. Las habitaciones más jerarquizadas se localizan sobre la fachada y poseen grandes aberturas que definen la imagen de la esquina. En esta casa también se distinguen cambios tipológicos, no solo en cuanto a la compactación de su espacio sino, fundamentalmente, en la complejidad del programa arquitectónico al fusionar trabajo y residencia.

La fachada marca una evolución de su autor hacia las líneas despojadas y puras de la arquitectura moderna de influencia mendelsoniana, aunque mantiene la composición de un basamento de mármol con un claro desarrollo de los dos niveles superiores y el remate de una gran faja horizontal. El zócalo que sirve de base se presenta fuerte, con un intenso peso morfológico debido al revestimiento en mármol. 
Los pisos superiores jerarquizan el tratamiento de la esquina con un volumen curvo con aventanamiento horizontal. Los laterales de las composiciones están ritmados por aberturas que con un desprejuiciado uso de arcos con balcones de rejas atenúan la soberbia pureza de volúmenes característicos del MoMo.

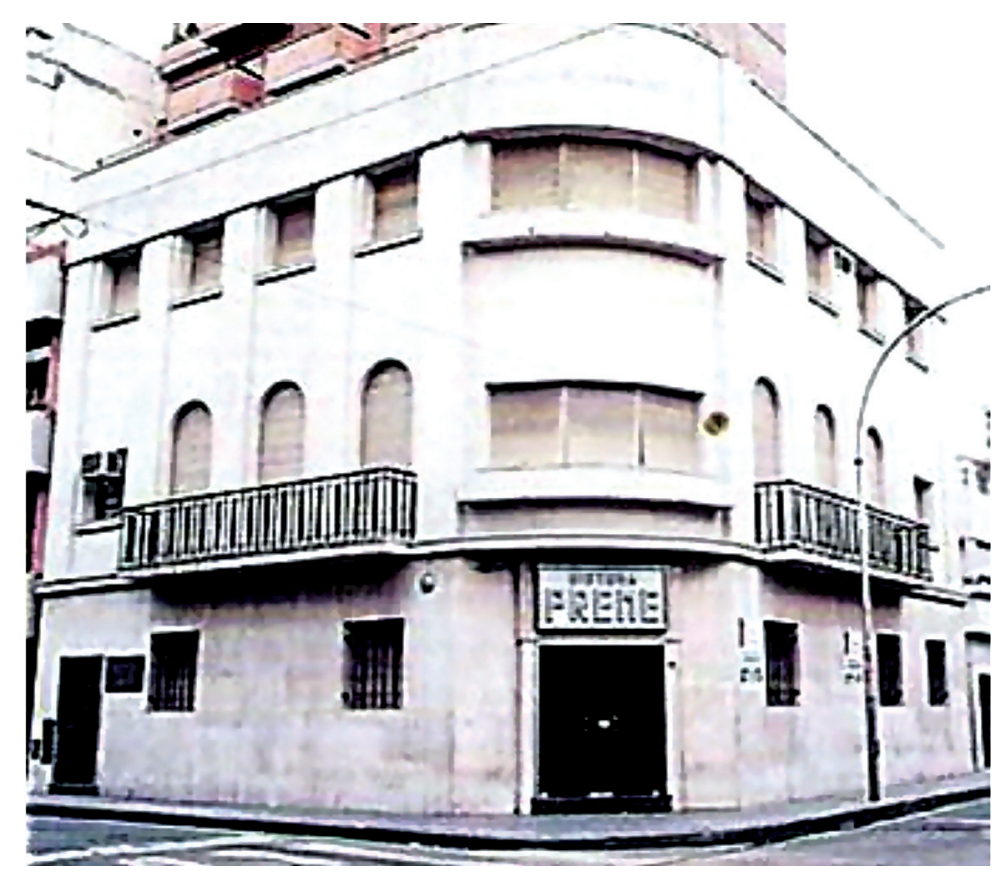

Figura 3. Casa Sayago (1938), centro Córdoba, Argentina. Fuente: autores.
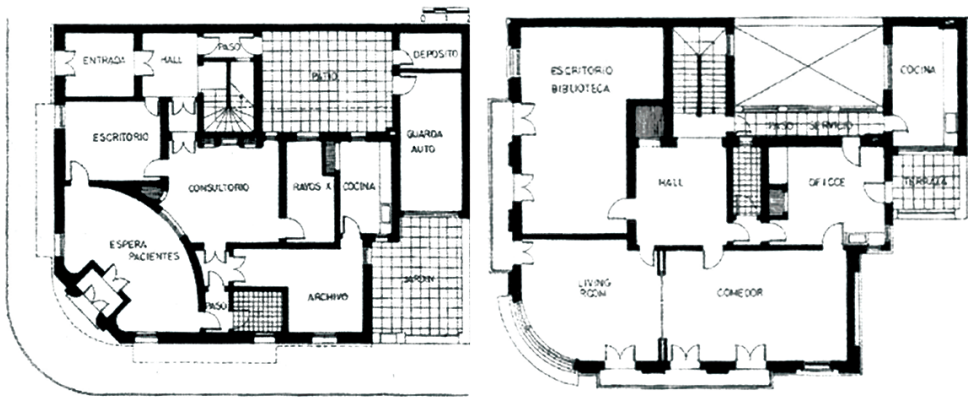

Figura 4. Plantas de la casa Sayago. Fuente: autores. 


\section{ROSARIO}

A partir de 1850 esta ciudad experimenta un acelerado crecimiento determinado por varios factores: el puerto, los ferrocarriles, su condición agroexportadora y el desarrollo del comercio. Este proceso se evidencia en el ímpetu de la arquitectura con gran cantidad de obras, además de las primeras ordenanzas municipales para reglamentar la construcción y el ejercicio profesional. En las primeras décadas del siglo XX hay una constante marcada por la especulación inmobiliaria como una forma de colocar excedentes de capital. Durante la década del treinta comienzan a aparecer las primeras manifestaciones del Art Decó, lo cual marca un punto de inflexión y transición hacia la nueva arquitectura. Esta, caracterizada por volúmenes despojados de todo tipo de ornamentación, adscribe a los postulados del MoMo y se difunde a partir de El constructor de Rosario, revista en que aparecen balcones redondeados, ventanas tipo ojo de buey o bien corridas en tiras horizontales, elementos geométricos, simples, puros y blancos. El movimiento se desenvuelve en medio de polémicas y debates.

\section{Un autor de la periferia en Rosario: Ermete De Lorenzi}

Ermete De Lorenzi, protagonista de la escena rosarina durante la tercera década del siglo, planteó la necesidad de adaptar la arquitectura a las circunstancias del momento. En su libro Fundamentos de teoría arquitectónica (1928), critica ampliamente las propuestas "nudistas" y "maquinistas" en una obvia alusión a la obra de Le Corbusier.

De Lorenzi comenzó su actividad profesional en un momento de transición en que el replanteo tipológico de la vivienda y su lenguaje eran protagonistas de la escena arquitectónica local. Por otra parte, en todos sus proyectos de vivienda unifamiliar debió tener en cuenta una condicionante debida a la escala, definida por las mínimas dimensiones de lotes céntricos, generalmente entre medianeras, los cuales exigían resoluciones tipológicas novedosas. Este replanteo tipológico vio evolucionar el programa arquitectónico en que la cuestión de género del siglo XIX -espacios masculinos a la calle y con mayor iluminación- es poco a poco relegada hasta llegar a un programa equilibrado para el desarrollo de la vida familiar.

El lenguaje formal de sus obras recorre diferentes repertorios que van desde el uso de hormigón a la vista, piedra, ventanas corridas y terrazas jardín, con una hábil utilización de aleros como elemento de articulación entre el interior y el exterior. Se destaca el manejo de la espacialidad, mediante escaleras tratadas como grandes esculturas despegadas de la caja muraria que vinculan la vida social con la familiar. 
Casa de sus padres. Es una vivienda urbana implantada en un lote en esquina, lo cual permite un despliegue formal gracias a la articulación volumétrica. Obra de 1928 ubicada en la Avenida Córdoba 2019, observa una tipología de petit hotel francés que mantiene rasgos compositivos académicos, con predominancia de un eje de simetría marcado por un espacio absidal, protagonista de la composición. De Lorenzi replantea la tipología a partir de una revisión de la escala -debido a la necesidad de construir en lotes de menores dimensiones- como también de la distribución de los locales para generar una nueva relación espacial entre ellos. La vivienda se resuelve en dos niveles: en la planta baja se encuentran los espacios sociales, las estancias principales (escritorio, sala) hacia la calle y los servicios (cocina, comedor) hacia el interior del lote. En la planta alta está dispuesto lo privado (dormitorios). Sorprende en esta resolución que el ábside, protagonista formal y espacio de mayor jerarquía en la planta baja, se convierta en la alta en un simple corredor de distribución de las habitaciones.

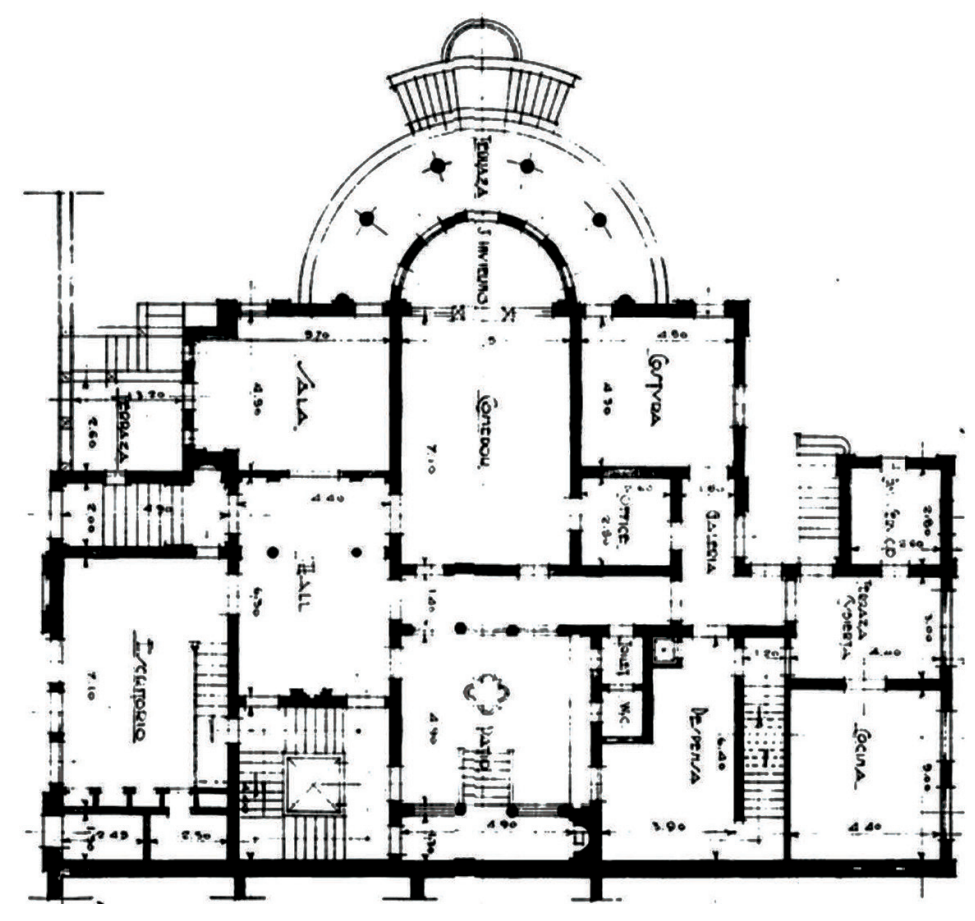

Figura 5. Planta de la casa de sus padres (1928), Rosario, Argentina. 


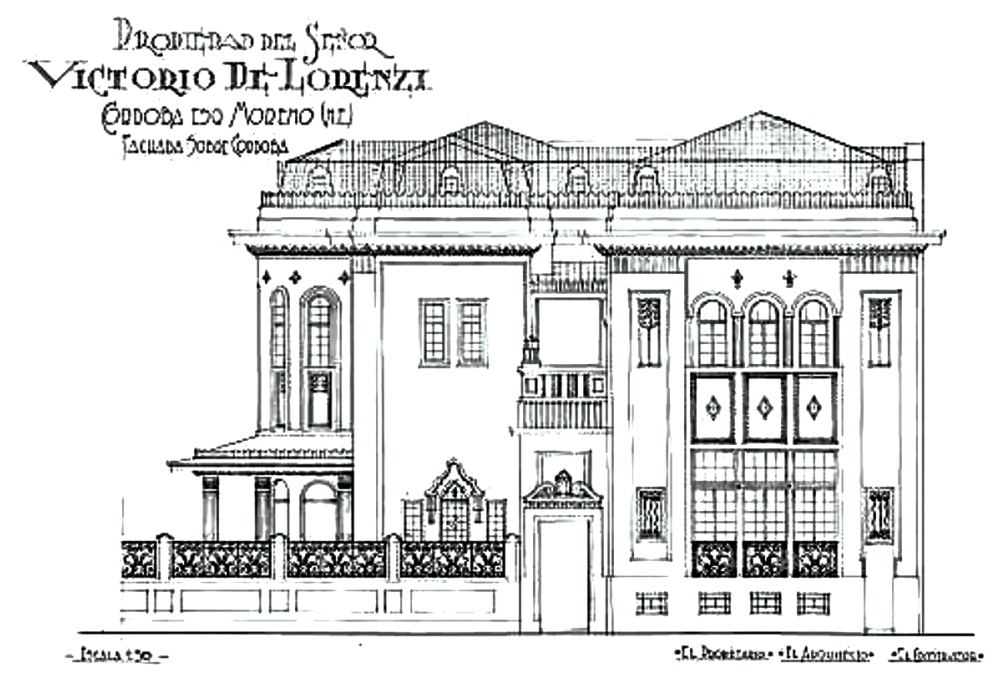

Figura 6. Elevación de la casa de sus padres.

Fuente: autores.

La fachada se resuelve en un lenguaje ecléctico en el que predomina una clara verticalidad de los paños y se insinúa un interesante manejo de recursos expresivos art decó. La composición evidencia la influencia académica. Una franja horizontal sirve de base a una logia circular que ritma el protagonista volumen circular con visuales hacia el jardín. El plano principal de fachada está divido en tres grandes paños, de los cuales el central, más estrecho, enmarca el ingreso principal. Uno de los laterales aparece más trabajado y delimitado por pilastras verticales que encierran ventanas rematadas por paños cuadrados con rombos circunscriptos, los cuales separan las ventanas de ambos niveles. El remate superior, definido por una cornisa quebrada, permite ver un juego de techos de distintas alturas.

Casa Eduardo Grimaldi. Situada en Balcarce 1765 de Rosario, se realizó entre 1937 y 1938 en un lote urbano entre medianeras. En esta casa compacta de dos plantas se observa una clara renovación tipológica. La planta baja, con el sector social, retrocede respecto de la línea municipal. El acceso principal es generado a partir de un jardín con intenciones higienistas de penetración de aire y luz. Un volumen saliente contiene el garaje. A diferencia del ejemplo previo, los ambientes más importantes se ubican en el interior al abrirse hacia el jardín mediante grandes ventanales que articulan 
los espacios y ofrecen visuales a la piscina. Los principios del MoMo se evidencian en el tratamiento formal. Así, se logra un volumen suspendido con aventanamiento corrido, piedra rústica de revestimiento de la planta baja da peso visual al único soporte del volumen de fachada que remata en una losa maciza en voladizo, remarca la horizontalidad del conjunto y expone una terraza a la manera corbusierana.

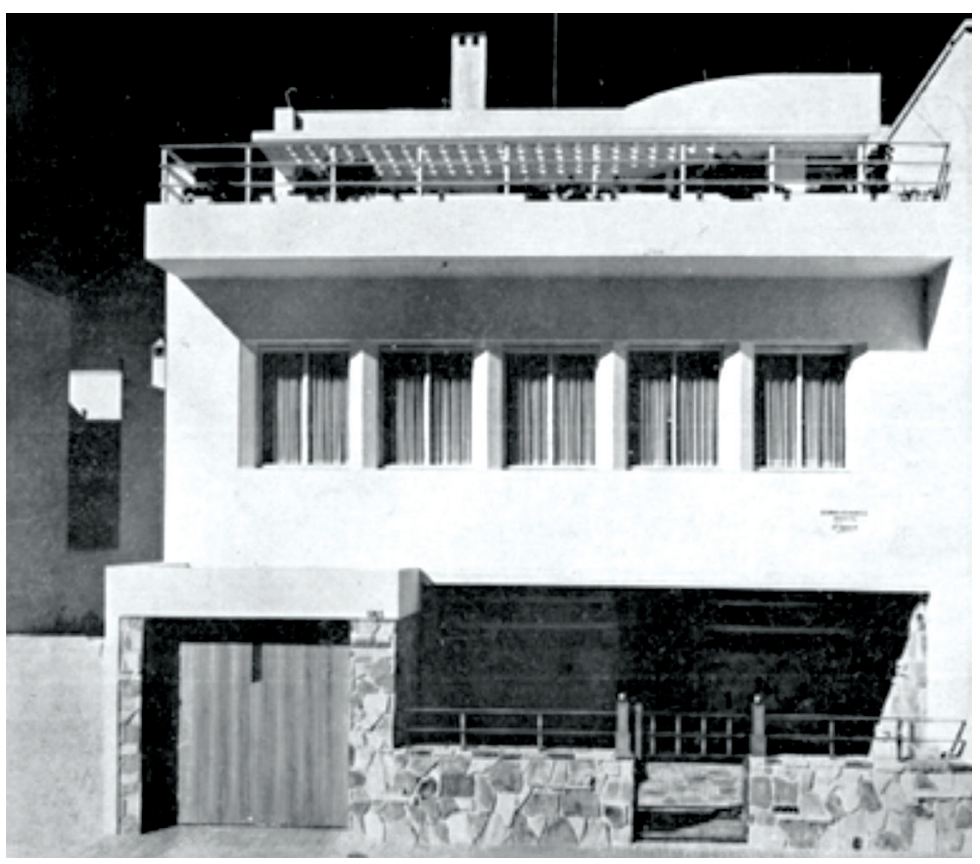

Figura 7. Fachada de la casa Eduardo Grimaldi (1937-38), Rosario, Argentina. 


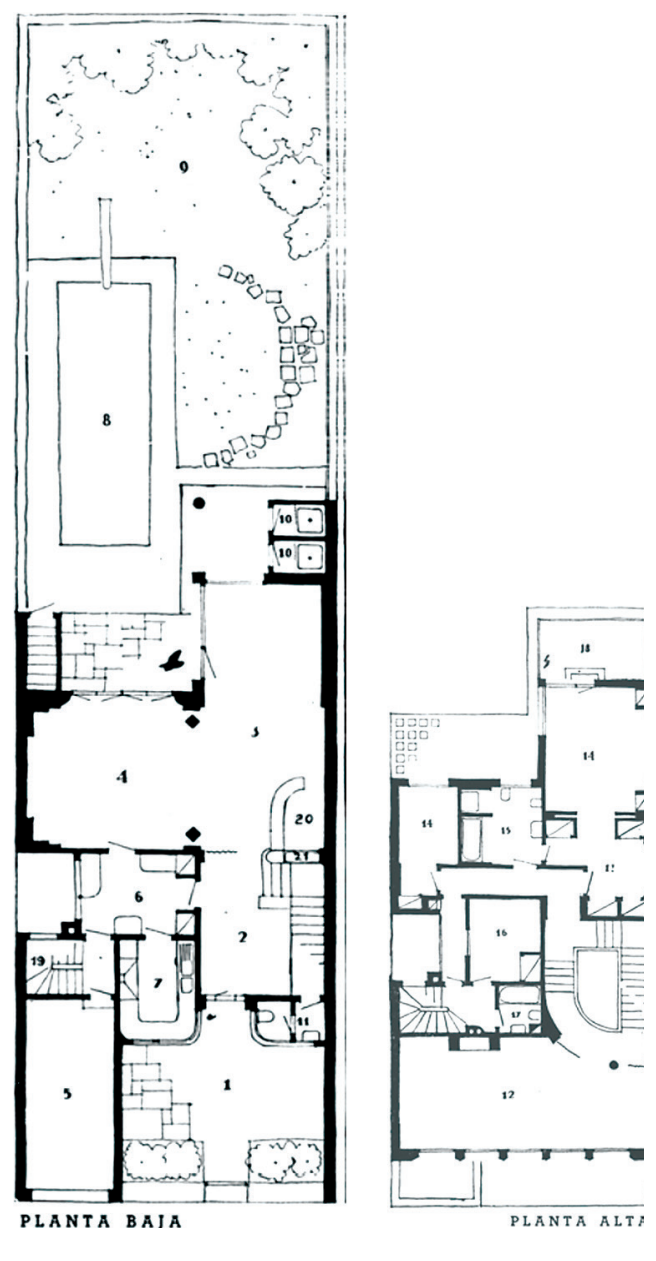

Figura 8. Plantas de la casa Eduardo Grimaldi.

Fuente: autores.

\section{TUCUMÁN}

Al igual que Córdoba, Tucumán tuvo durante la Colonia una condición periférica dentro del virreinato del Río de la Plata, con una sociedad conservadora y muy enraizada en sus tradiciones. "El jardín de la República", elegido como sede constituyente para la declaración de la Independencia, fue cuna propicia para el desarrollo de la civilización liberal decimonónica y, con ello, para la construcción de sedes institucionales en una arquitectura monumental e historicista, también fuertemente arraigada en el sector oficial hasta entradas las primeras décadas del siglo XX, cuando empezó a convivir con las primeras manifestaciones del MoMo. Esta nueva propuesta morfológica de vanguardia fue receptada lentamente desde el ámbito privado y canalizada por la actividad profesional de maestros locales 
como Eduardo Sacriste. Según Gutman (1987), al proponer un planteo funcional moderno y un lenguaje exterior vinculado a la tradición, muchas obras se acercaban a las primeras ideas de revalorización de la identidad local en medio de la transculturación de modelos europeos.

\section{Un autor de la periferia en Tucumán: Eduardo Sacriste}

La obra de Sacriste se caracteriza por una síntesis entre los principios rectores del MoMo y el legado de su propia región, el noroeste argentino: “Considero a mis obras simplemente discretas" (Petrina, 1985, p. 24-25). La reinterpretación y revalorización de tipologías y programas; el respeto por las tradiciones geográficas, sociales, culturales y constructivas; una intensa valoración de historias, mandatos climáticos y la memoria de la producción popular; todo ello genera una arquitectura que se adapta y adecúa al MoMo. Al mismo tiempo, se libera de la dependencia dogmática y esclavizante de las modas para poner énfasis en lo local, en un gesto poco común entre los arquitectos de su generación. Su trabajo de alta calidad se traduce en un diálogo con el entorno sin precedentes en Argentina hasta aquel momento.

Casa Terán Etchecopar. Construida en San Miguel de Tucumán entre 1936 y 1939, corresponde a la tipología de vivienda unifamiliar desarrollada en un lote urbano entre medianeras. En esta, una de sus primeras obras, inspirada según el autor en la Villa Stein de Le Corbusier, aparece el patio como generador de espacios, elemento característico de la arquitectura de Sacriste. La casa retrocede respecto de la línea municipal con un gran vacío, enmarcado por ingresos laterales diferenciados, uno peatonal y otro vehicular, que sirve de generador de un volumen simple, puro, en dos niveles. Con un programa sencillo para diferenciar la zona más pública en la planta baja (con garaje, living, cocina comedor y servicios), la sala de estar adquiere protagonismo al abrirse con grandes ventanales al jardín. La planta alta, más privada, posee los dormitorios y la terraza con vista al jardín.

La solución morfológica se da mediante la articulación de dos volúmenes puros, despojados, a los que en el segundo nivel se yuxtapone un prisma para dar origen al balcón. En esta obra temprana, si bien se expresa la adscripción a los postulados y lineamientos de la arquitectura moderna y funcional, se evidencia un tratamiento plástico con ritmo vertical en el aventanamiento. Igualmente, se descubre una incipiente búsqueda de elementos que luego serán protagonistas de las obras de este autor, como es el caso de la orientación condicionada por las dimensiones estrechas del lote, lo cual es resuelto hábilmente con sendos espacios verdes en la planta baja, los jardines y las terrazas. El plano de la fachada se distancia de la línea municipal por la presencia del jardín en el frente. 

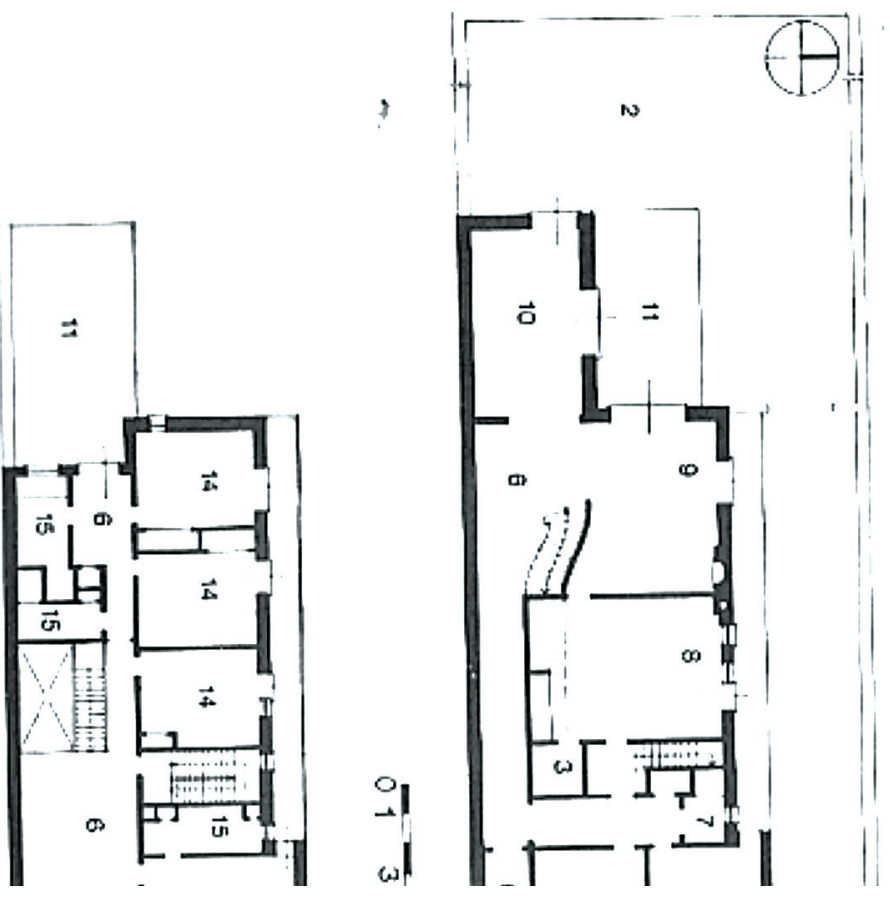

Figura 9. Planta de la casa Terán Etchecopar (1936-1939) San Miguel de Tucumán, Tucumán, Argentina. Fuente: autores.

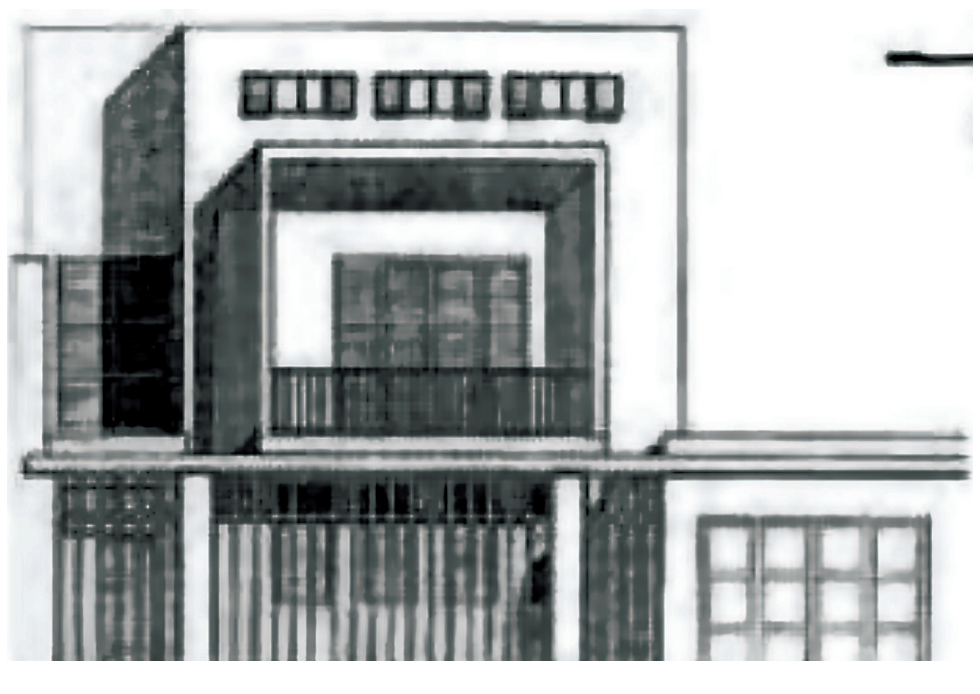

Figura 10. Elevación de la casa Terán Etchecopar. Fuente: autores. 
Casa Torres Posse. Realizada entre 1956 y 1958, esta obra se inserta en el medio rural de Tafi del Valle. El valle, rodeado por montañas, presenta un clima particular: en verano, las intensas lluvias resaltan el verde vivo de la vegetación, mientras que el invierno es frío y seco pero con sol radiante. Es pertinente destacar la presencia de plataformas circulares de $12 \mathrm{~m}$ de diámetro, restos de culturas precolombinas, pues la vivienda se planteó con un programa simple que aprovecha una de estas estructuras. Así, se desarrolla en dos volúmenes puros, articulados y girados entre sí. Uno de ellos tiene un solo nivel donde se alojan las actividades sociales y el garaje del automóvil, en tanto el otro alberga el área mas privada con los dormitorios. Esta casa reinterpreta los postulados del MoMo y en una excelente síntesis los adapta a las condicionantes de una región periférica.

Orientada según el eje norte-sur, la casa plantea su adaptación a la topografía del lugar por medio de desniveles. A su vez, la amplia galería que se cierra hacia el sur con un vidrio fijo, como protección frente a los vientos, enmarca la vista hacia uno de los montes más importantes del valle. Distintas visuales del paisaje son igualmente enmarcadas mediante pequeños vanos calados en los pétreos muros portantes. Estos, hechos con piedra del lugar, dejan a la vista el aspecto rústico del material en una actitud de mímesis con el entorno. El techo aparece con un remate fuerte, lineal y horizontal, a partir del uso de una losa de hormigón armado con cubierta de barro que actúa como aislante térmico.

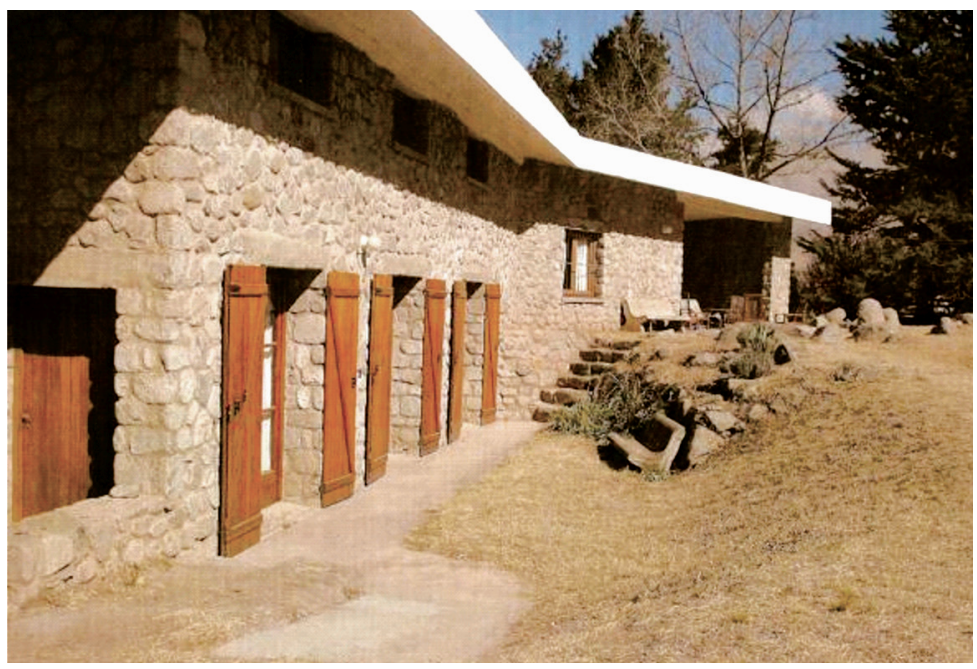

Figura 11. Casa Torres Posse (1956-1958). Tafi del Valle, Tucumán, Argentina. 


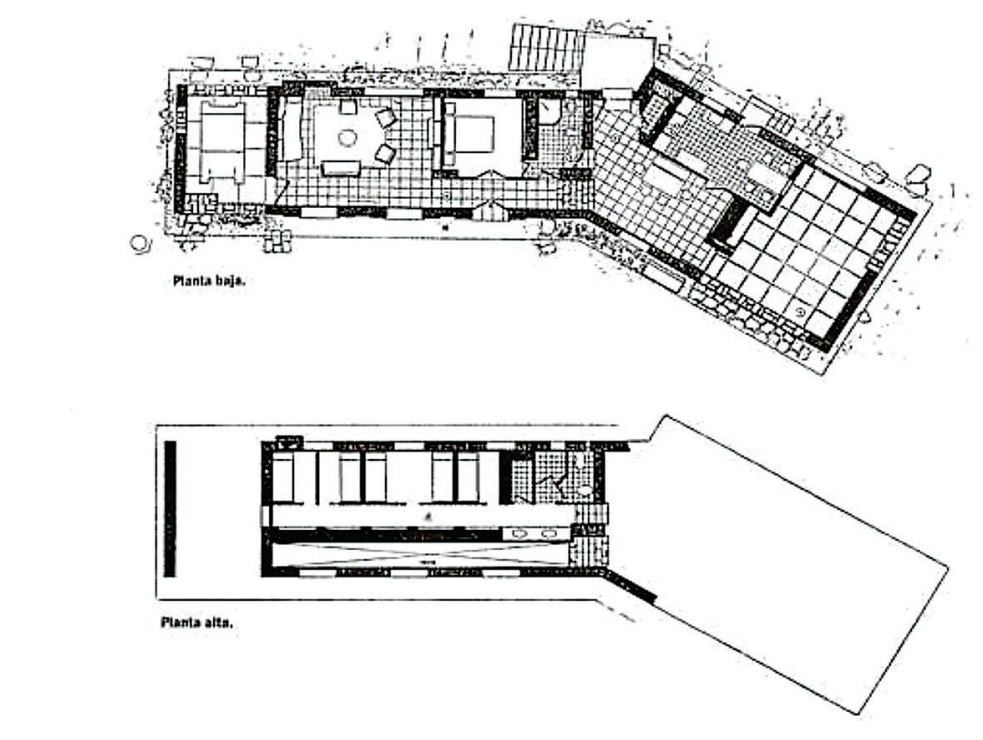

Figura 12. Planta de la casa Torres Posse.

Fuente: autores.

\section{CONCLUSIONES}

A través de la centralidad de Buenos Aires, en las primeras décadas del siglo XX Argentina se encuentra insertada en el proyecto moderno internacional y participa, consciente o inconscientemente, de aciertos, desaciertos y contradicciones. En esta coyuntura nacional existen múltiples actores y escenas y resulta evidente que las distintas realidades -no solo geográficas, sino también sociales, culturales y económicas- llevan a las periferias a diferenciarse entre sí. Córdoba y Rosario son, en relación con la capital del país, "otras periferias": ciudad universitaria e industrial la primera y centro portuario la segunda. A su vez, cuando estas actúan como "otros centros" se distinguen de realidades en que la región prevalece por encima de todo. Tal es el caso de los tipos arraigados en la vivienda del noroeste argentino, donde la tradición sobresale por encima de cualquier otra cualidad.

Los autores experimentan una inmersión cultural y geográfica que no pueden omitir: son producto de una realidad y a esta se superpone la vanguardia planteada por el MoMo. En mayor o menor medida, la vivienda los representa ante un ambiente humano urbano resultante de los nuevos modelos y la innovación. Muchas veces, la tradición preexistente supera al lenguaje mas no al "tipo", el cual permanece en la médula de la concepción de esa sede particular de la institución familiar. La búsqueda de equilibrio entre las influencias de la región-periferia y el centro-universal depende de la mayor o menor permeabilidad que cada arquitecto tenga. 
El MoMo planteó una revisión de los movimientos de fines del XIX y principios del XX, los cuales sintetizó en un nuevo modo de producción, pero sobre todo en la forma de concebir la vivienda. Esa concepción fue permeable a profundas transformaciones: la reducción de la escala por la inserción urbana en lotes de diferentes dimensiones, la variación de roles en la vida familiar, la prioridad dada a la función por encima de la forma y el cambio simbólico, al despojarse de toda carga significativa preexistente.

Los autores estudiados lograron resultados singulares para responder a una época en que el replanteo tipológico y el lenguaje de la vivienda fueron protagonistas en las escenas arquitectónicas locales. Varios maestros adhirieron paulatinamente a las vanguardias, como sucedió en Córdoba y Rosario, donde el Art decó fue recibido hasta alcanzar los ideales modernos. Pero también en la periferia de las periferias -el noroeste- se supo dar una impronta de reflexión y mestizaje de la mano de "otros maestros", lo cual abrió las puertas, seguramente, a otro momento de vanguardia "interna" como fue el nacimiento de la postura de los regionalismos.

Se considera que el valor esencial de esta producción arquitectónica es reflejar los principios del MoMo en tantos y diferentes modos. También se destaca la capacidad de cada exponente de entender la concepción lingüística y los paradigmas de este movimiento al hacer su transferencia a una realidad concreta, a la propia realidad.
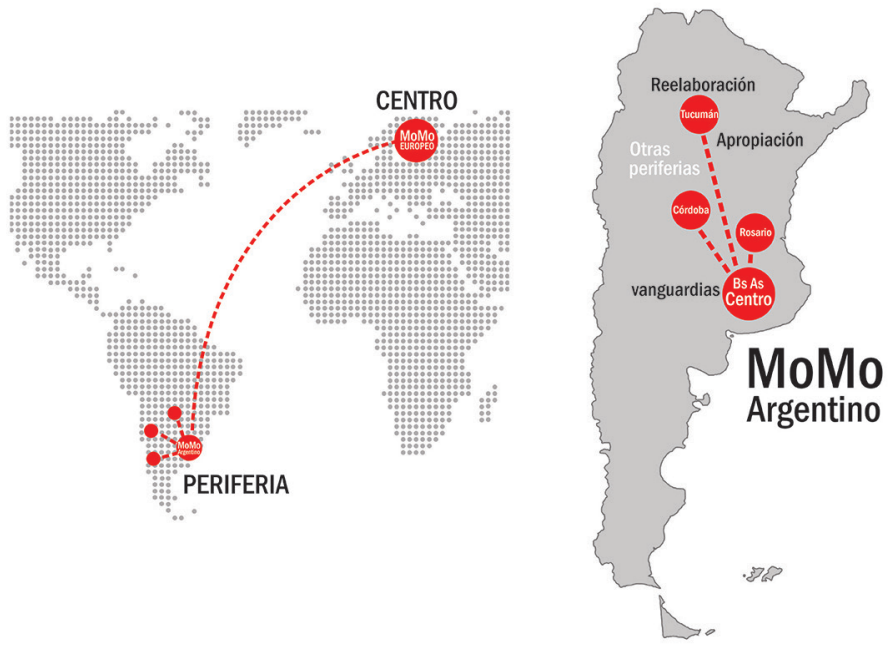

Figura 13. Procesos de transculturación del MoMo europeo a Argentina. 


\section{REFERENCIAS BIBLIOGRÁFICAS}

Browne, E. (1988). Otra Arquitectura en América Latina. México: Gustavo Gili.

Colautti, V. (2002). Orden y complejidad como instrumentos estratégicos del proceso de diseño en el paisaje urbano del siglo XXI. Tesis de Maestría, Universidad Nacional de Córdoba, Argentina.

De Lorenzi, E. (1928). Fundamentos de teoría arquitectónica. Rosario. Editorial Rosario.

Doberti, R. (2008). Espacialidades. Buenos Aires: Infinito.

Gutiérrez, R. (2002). Arquitectura y urbanismo en Iberoamérica. Madrid: Cátedra.

Gutman, M. (1987). Noel: ese desconocido. Anales del Instituto de Arte Americano e Investigaciones Estéticas Mario J. Buschiazo, (25), 48-58.

Liernur, J. F. (2008). Arquitectura en la Argentina del siglo XXI. La construcción de la modernidad. Buenos Aires: Fondo Nacional de las Artes.

Mele, J. (2005). Vanguardias argentinas, obras y movimientos. Buenos Aires: Arte Gráfico AGEA.

Montaner, J. M. (2011). Arquitectura y crítica en Latinoamérica. Buenos Aires: Nobuko.

Romero, L. A. (1997). Latinoamérica: las ciudades y las ideas. Buenos Aires: Siglo Veintiuno.

Petrina, A. (1985). Eduardo Sacriste: la obra de un maestro. Summa, (220), p.24-25. Buenos Aires.

Sarlo, B. (1988). Una modernidad periférica: Buenos Aires 1920 y 1930. Buenos Aires: Nueva Visión.

Trecco, A. (1979). Tipologías arquitectónicas desde Grecia al siglo XIX. Monografía de grado, Universidad Nacional de Córdoba, Argentina.

Vautier, E. \& Prebisch, A. (1924). Ensayo de estética contemporánea. Revista de Arquitectura, (47). Buenos Aires.

Waisman, M. (1995). La arquitectura descentrada. Historia y Teoría Latinoamericana. Editorial Escala. Bogotá, Colombia. 